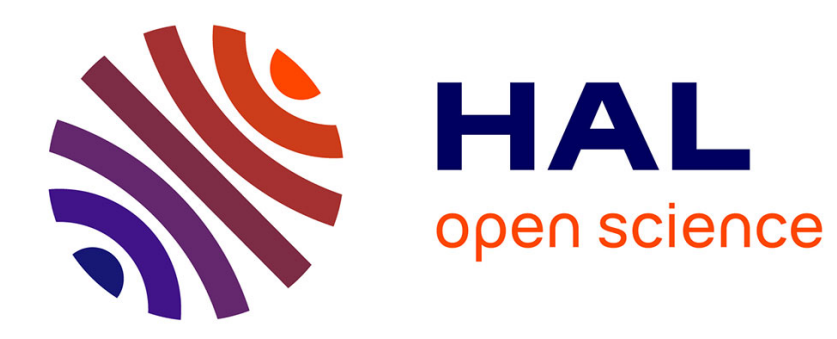

\title{
Monopolization through acquisitions in a differentiated product industry
}

Emilie Dargaud

\section{To cite this version:}

Emilie Dargaud. Monopolization through acquisitions in a differentiated product industry. 2005. halshs-00180041

\author{
HAL Id: halshs-00180041 \\ https://shs.hal.science/halshs-00180041
}

Submitted on 17 Oct 2007

HAL is a multi-disciplinary open access archive for the deposit and dissemination of scientific research documents, whether they are published or not. The documents may come from teaching and research institutions in France or abroad, or from public or private research centers.
L'archive ouverte pluridisciplinaire HAL, est destinée au dépôt et à la diffusion de documents scientifiques de niveau recherche, publiés ou non, émanant des établissements d'enseignement et de recherche français ou étrangers, des laboratoires publics ou privés. 


\title{
DOCUMENTS DE TRAVAIL - WORKING PAPERS
}

\author{
W.P. 05-07
}

\section{Monopolization through acquisitions in a differentiated product industry}

Emilie Dargaud

Juin 2005

GATE Groupe d'Analyse et de Théorie Économique UMR 5824 du CNRS

93 chemin des Mouilles - 69130 Écully - France

B.P. $167-69131$ Écully Cedex

Tél. +33 (0)4 72866060 - Fax +33 (0)4 72866090

Messagerie électronique gate@gate.cnrs.fr

Serveur Web : www.gate.cnrs.fr 


\title{
Monopolization through acquisitions in a differentiated product industry
}

\author{
DARGAUD Emilie* \\ GATE $^{\dagger}$ \\ University Lyon 2
}

\begin{abstract}
This article analyzes the incentive to merge in a context of price competition with horizontal product differentiation. In contrast to the results obtained by Kamien and Zang (1990), we show that merged equilibria can appear in this game. Moreover monopolization of the industry occurs with a high number of firms.
\end{abstract}

Keywords: Mergers; Oligopoly; Cooperative game

JEL classification: L10; L11; L20

\footnotetext{
${ }^{*}$ Tel.: +33(0)472866037 ; fax: +33(0)472866090 ; e-mail: dargaud@gate.cnrs.fr

${ }^{\dagger}$ Groupe d'Analyse et de Théorie Economique, UMR 5824 du CNRS -93, chemin des mouilles, 69130 Ecully- France
} 


\section{Introduction}

In a famous paper, Salant, Switzer and Reynolds (1983) have reported that in a Cournot oligopoly with homogeneous products, linear demand and cost functions, a merger is beneficial for participating firms if more than 80 per cent of all firms merge. It is because outsiders are more beneficial than the firms participating to the merger, the "insiders". Since production costs are linear, any coalition of firms is indifferent with respect to the way of splitting its total production among the members of the coalition, so, every coalition of firms behaves as if it were a single firm.

Perry and Porter (1985) but also Farrell and Shapiro (1990) have challenged the view that a merged firm is no larger than any of the constituent firms. These studies introduce the existence of some crucial assets that are in limited supply in order to capture the notion that some firms are larger than others in a homogeneous product industry. This assumption implies rising marginal cost of output production and, consequently, internal cost savings from mergers could make a merger profitable.

Deneckere and Davidson (1985) have found an opposite result in the case of price competition with differentiated products where a merger is always beneficial for the insiders.

Kamien and Zang (1990) have explored the possibility of endogenous monopolization of a homogeneous good Cournot oligopoly through one firm's acquisition of the others. They adopt two different approaches : firstly, an analysis of a centralized game : an owner who acquired several firms behaves as one entity (as in SSR, 1983). Secondly, they explore the possibility for an owner, possessing several firms, to choose the optimal number of active firms, each of them competing with each other : it is the decentralized game. More precisely, in this kind of game, they emphasize that an owner, possessing several firms, chooses to operate more than one firm. They disclose that, for the two kinds of game, monopolization can only occur in industries composed 
ex-ante of a small number of firms. Moreover, in the centralized game (SSR context (1983)) with a large number of firms, merged equilibria (that means the number of active firms is fewer than the initial number of firms) are non-existent which reinforce the SSR's results (1983).

In Kamien and Zang (1993), a sequential noncooperative game in which the centralized game is played over and over is considered. They show that monopolization of the industry is impossible if the initial number of firms is relatively high.

A more recent literature takes into account strategic delegation (GonzalezMaestre and Lopez-Cunat (2001) or Ziss (2001)) to study merger profitability. What differs to the decentralized game in Kamien and Zang (1990) is the two types of competition : in the production and in the remuneration of managers. The delegation increases competition between entities inside the firm. Consequently, the incentives to merge and the profitability of merger, under delegation, are considerably increased with respect to the setting without delegation. Ziss (2001) argues that a merger will result in the merged entity operating only one firm.

Commitment through delegation may be limited by the possibility to renegotiate delegation contract in the absence of a strong enforcing institutional setting avoiding false disclosure and private renegotiation. Precommitment effects seem to rest on the crucial assumption that contracts, once publicly disclosed, cannot be secretly renegotiated. But this is at odds with reality: whether legally enforceable or of a more implicit nature, actual contracts can almost always be renegotiated if both parties agree (Caillaud, Jullien and Picard, 1995). In the same way, in the decentralized game of Kamien and Zang (1990), internal competition is not credible because if contracts were renegotiable ex-post, firms may act cooperatively. In our model, we consider that firms belonging to the same owner play in a cooperative way. 
Our purpose is to analyse the incentives to merge in a context of price competition with horizontal product differentiation. As in Kamien and Zang (1990), a three-stage game is considered.

We study merger profitability by assuming that an owner of several firms chooses the number of firms he lets active. This optimal number is endogenously determined to maximize merger profit. The number of active firms plays a major role : since products are horizontally differentiated, demand increases with the number of active firms so a merger can gain market shares, but equilibrium price is lower. Active firms create internal competition but reinforces competition with the other firms in a same time.

We consider market structure with a high number of firms. We show that merged equilibria can appear in this game. Moreover monopolization of the industry occurs with this high number of firms. This is in contrast to the results obtained by Kamien and Zang (1990) who demonstrated that no merged equilibrium exists in a centralized game and that monopolization never occurs for a sufficiently large number of firms in their games (neither centralized nor decentralized).

The article is organized as follows. Section 2 presents the model. Characterizations of equilibrium are provided in section 3. Concluding remarks follow. Proofs of results appear in the appendix.

\section{The model}

We consider the following utility function derived from Häckner (2000) :

$$
U(\mathbf{q}, I)=\sum_{i=1}^{n} q_{i}-\frac{1}{2}\left[\sum_{i=1}^{n} q_{i}^{2}+2 \gamma \sum_{i \neq j}\left(q_{i} q_{j}\right)\right]+I
$$

The parameter $\gamma \in[0,1]$ measures the substitutability between the products. Utility is quadratic in the consumption of the $n$ horizontally differentiated products and linear in the consumption of others goods: $I$, which 
price is normalized to one.

Demand function is :

$$
q_{i}\left(p_{i}, p_{j}, n\right)=\frac{1}{1+\gamma(n-1)}\left[1-\frac{1+\gamma(n-2)}{1-\gamma} p_{i}+\frac{\gamma}{1-\gamma} \sum_{j \neq i} p_{j}\right]
$$

We assume that entry into the industry is difficult and that each producer operates at a constant and identical marginal and average cost of c. Without loss of generality, we assume that $c=0$. All the relevant variables and strategies available to the firms are common knowledge.

We posit an initial industry consisting of $n=16$ identical and independent firms.

Let us now turn to the formal description of our three-stage game.

- Stage 1 : bidding stage.

One or two firms make offers simultaneously to other firms and each firm sets a ceasing price for its own firm. Each shareholder computes his willingness to pay for one, two, three or more firms.

Let $K_{j}$ be the number of firms owned by a merger $M_{j}$ and $Z$ the number of outsiders which have not been bought.

A firm ' $j^{\prime}$ is sold to ' $i$ ' if the bid of ' $i$ ' is not smaller than the asking price and if it is the highest bid for this firm, it is sold to the willingness to pay of the buyer.

The allocation of firm ${ }^{\prime} i$ is independent of the asking prices and bids received by every other firm. In the presence of tie, firm ' $i$ ' is not sold. A market structure is a Nash equilibrium in this subgame if no firm is able to purchase one or several firms and the others accept.

We authorize successive bidding by one or two firms until the equilibrium is reached.

- Stage 2: merger stage.

Each owner decides the number of his active firms. 
Let $k_{j}\left(0 \leq k_{j} \leq K_{j}\right)$ be the number of active firms owned by $M_{j}$. A SPNE (Subgame Perfect Nash Equilibrium) in an acquisition game is said to be merged if the number of firms operated by all owners is fewer than the initial number of firms.

- Stage 3: competition stage.

Firms belonging to the same owner act cooperatively amongst one another but face competition with each other. The active firms in mergers and the outside firms compete in price.

We characterize pure strategy subgame perfect Nash equilibria of this game.

\section{Analysis of equilibria}

This section characterizes the set of equilibria.

proposition 1. At equilibrium, monopolization of the industry occurs.

We prove this result and exhibit two trajectories which conduct to the monopolization equilibrium. The first allows two firms to make bids on the others. The second allows only one firm to bid on the others.

\subsection{Indirect monopolization}

In this section, we consider the case where two mergers denoted $M_{1}$ and $M_{2}$ can buy firms. Each of them operates respectively $k_{1}$ and $k_{2}$ units. There are $Z$ outside firms.

\subsubsection{Equilibrium prices}

$M_{1}, M_{2}$ and the outside firms simultaneously choose the price of each of their firm seeking to maximize their profit. 
lemma 1. Equilibrium prices of the two mergers ( $p_{1}^{*}$ and $p_{2}^{*}$ ) and the outsiders $\left(p^{*}\right)$ are given by:

$$
\left\{\begin{array}{l}
p_{1}^{*}=\frac{(1-\gamma)\left(2+2(Z-1) \gamma+2 \gamma k_{1}+\gamma k_{2}\right)\left(2+(2 Z-3) \gamma+2 \gamma\left(k_{1}+k_{2}\right)\right)}{A} \\
p_{2}^{*}=\frac{(1-\gamma)\left(2+(2 Z-3) \gamma+2 \gamma\left(k_{1}+k_{2}\right)\right)\left(2+2(Z-1) \gamma+\gamma\left(k_{1}+2 k_{2}\right)\right)}{A} \\
p^{*}=\frac{(1-\gamma)\left(2+2(Z-1) \gamma+2 \gamma k_{1}+\gamma k_{2}\right)\left(2+2(Z-1) \gamma+\gamma\left(k_{1}+2 k_{2}\right)\right)}{A}
\end{array}\right.
$$

with

$$
\begin{aligned}
& \quad A=2 \gamma^{2} k_{1}^{2}\left(4-4 \gamma+3 Z \gamma+3 \gamma k_{2}\right)+2\left(1+(Z-1) \gamma+\gamma k_{2}\right)(2(2+(Z-3) \gamma)(1+ \\
& \left.(Z-1) \gamma)+\gamma(4-4 \gamma+3 Z \gamma) k_{2}\right)+\gamma k_{1}\left(2(8+5(Z-2) \gamma)(1+(Z-1) \gamma)+\gamma k_{2}(22-\right. \\
& \left.\left.25 \gamma+17 Z \gamma+6 \gamma k_{2}\right)\right) .
\end{aligned}
$$

We check that $A>0$.

Proof. See Appendix A.

Equilibrium profit of the merger $M_{1}$ is given by:

$$
\begin{array}{r}
\pi^{M_{1}}=\frac{1}{\left(1+\gamma\left(k_{1}+k_{2}+Z-1\right)\right) A^{2}}(1-\gamma) k_{1}\left(1+(Z-1) \gamma+\gamma k_{2}\right) \\
\left(2+2(Z-1) \gamma+2 \gamma k_{1}+\gamma k_{2}\right)^{2}\left(2+(2 Z-3) \gamma+2 \gamma\left(k_{1}+k_{2}\right)\right)^{2}
\end{array}
$$

The expression for merger $M_{2}$ is symmetric.

\subsubsection{Merger phase}

We now determine if an owner of several firms will choose to close some of them or to keep all of them active.

\section{proposition 2.}

- If $Z \geq 2$ then merged equilibria can not occur in this game.

- If $Z<2$ the game can result in merged equilibria depending on the products substitutability. Merged equilibria can appear when the products are not too much differentiated.

Proof. See Appendix B. 
The existence of merged equilibria depends on the number of outsiders. Precisely, the presence of outsiders increases the competitive pressure, so when the number of outsiders is high enough $(Z \geq 2)$, an owner of several firms will not close some of them to maintain its market power.

In the following of the paper, we assume $\gamma=0.9$ in order to study all the different cases (merged or unmerged equilibria).

The objective now is to analyse if the number of firms owned by the mergers influences the number of firms they will let active.

Let us define the reaction function of the merger $M_{1}: k_{1}^{*}\left(k_{2}\right)$.

lemma 2. The reaction function of the merger $M_{1}$ is:

$$
\boldsymbol{k}_{1}^{*}\left(\boldsymbol{k}_{2}, \boldsymbol{Z}\right)=\left\{\begin{array}{l}
K_{1} \text { if } Z>1, \forall k_{2} \\
f\left(k_{2}\right)<K_{1} \text { if } Z=1 \text { and } k_{2} \geq 8 \\
K_{1} \text { if } Z=1 \text { and } k_{2}<8 \\
g\left(k_{2}\right) \text { if } Z=0
\end{array}\right.
$$

The proof is obtained by numerical simulations. Appendix $\mathrm{C}$ gives the exact values of functions $f$ and $g$ as well as values of profit functions.

The reaction function of the merger $K_{2}$ is a symmetrical function of $k_{1}^{*}\left(k_{2}\right)$.

We observe that $k_{1}^{*}\left(k_{2}\right)$ is a decreasing function, so $k_{1}$ and $k_{2}$ are strategic substitutes.

\subsubsection{Bidding stage}

We suppose initially that each of the two shareholders $M_{1}$ and $M_{2}$ owns one firm and can not sell it; only the outside firms can be sold but only in their entirety. Each of the two shareholders simultaneously sets a vector of bids facing the number of firms owned by the other, that means, facing $K_{2}$ firms, the first shareholder has to decide how many firms to purchase.

After a deal, each shareholder owns one or more firms $\left(K_{j} \in(1,15), Z \in\right.$ 
$(0,14))$.

Transactions occur in this acquisition stage until no additional purchase by one of the first two firms can be realized. The equilibrium condition is then defined by :

$$
W T P_{M_{i}}\left(K_{1}, K_{2}, Z\right)<W T S_{\text {out }}^{M_{i}}\left(K_{1}, K_{2}, Z\right), \forall i=1,2 .
$$

$W T P_{M_{i}}\left(K_{1}, K_{2}, Z\right)$ is the maximum price (Willingness To Pay) $M_{i}$ is willing to pay for buying $K_{i}-1$ firms, facing the other merger owning $K_{j}$ firms. It is defined by :

$$
W T P_{M_{i}}\left(K_{i}, K_{j}, Z\right)=\pi_{M_{i}}\left(K_{i}, K_{j}, Z\right)-\pi_{M_{i}}\left(1, K_{j}, Z+K_{i}-1\right)
$$

$W T S_{\text {out }}^{M_{i}}\left(K_{1}, K_{2}, Z\right) \forall i=1,2$ is the total minimum selling price (Willingness To Sell) of outsiders towards the merger $M_{i}$ and is expressed as :

$W T S_{\text {out }}^{M_{i}}\left(K_{i}, K_{j}, Z\right)=\pi_{\text {out }}\left(K_{i}-1, K_{j}, Z+1\right) *$ nbr of firms bought

The selling price of an outsider firm depends on the number of firms the two owners want to buy. More precisely, when the outsider sets its selling price, he forestalls his profit in the last stage if it declines the offer considering all the other firms the owner wants to buy have accepted and considering that the owner which buy others can close some of them after.

\section{lemma 3.}

- Mergers $M_{1}$ and $M_{2}$ buy all the outside firms so as to get : $K_{1}+K_{2}=16$ $(Z=0)$.

- Since $K_{1}+K_{2}=16$ only market structures wherein one owner lets all his firms active and the other closes some of his firms can occur. 
However, these structures are not Nash equilibria because the owners of $M_{1}$ and $M_{2}$ can benefit from purchasing themselves.

Facing $K_{2}$, we compute the willingness to pay of $M_{1}$ to purchase $M_{2}$ in its entirety.

$$
W T P_{M_{1}}^{2^{\text {nd }}}\left(K_{1}, K_{2}, 0\right)=\pi_{M_{1}}(16,0,0)-\pi_{M_{1}}\left(K_{1}, K_{2}, 0\right)
$$

where $W T P_{M_{1}}^{2^{n d}}\left(K_{1}, K_{2}, 0\right)$ is the willingness to pay of $M_{1}$ and $\pi_{M_{1}}\left(K_{1}, K_{2}, 0\right)$ designs the duopoly profit of $M_{1}$.

$M_{2}$ is willing to sell its merger at any price above its profit : $\pi_{M_{2}}\left(K_{1}, K_{2}, 0\right)$.

$M_{1}$ will purchase $M_{2}$ if :

$$
W T P_{M_{1}}^{2^{n d}}\left(K_{1}, K_{2}, 0\right)>\pi_{M_{2}}\left(K_{1}, K_{2}, 0\right)
$$

We compute this for all the different values of $K_{2}$ (with $\left.K_{1}+K_{2}=16\right)$ and we obtain the following proposition :

proposition 3. Monopolization of the industry:

- At equilibrium, only monopolization of the industry can occur.

- The only possible equilibria in this game consist of unmerged equilibria wherein one owner possessing all firms will let all of them active.

Proof. The first part is obtained by numerical simulations. The second is straightforward by considering : $\frac{\partial \pi^{M_{1}}}{\partial k_{1}}(16,0,0)>0 \Rightarrow k_{1}^{*}=K_{1}$.

\subsection{Direct monopolization}

In this section, we exhibit a second trajectory in which only firm $M_{1}$ makes bids in order to purchase other firms. The game is solved as previously.

\section{proposition 4.}

- The merger $M_{1}$ will buy all the outside firms so as to monopolize the market. 
- If the market results in a monopolization, then the owner will let active all his firms.

The first part of the proposition is verified comparing the willingness to pay of $M_{1}$ with the willingness to sell of all the outside firms. Proof of the second part is the same than for the previous proposition.

\section{Concluding Remarks}

We have considered the possibility of monopolization through acquisition in an industry composed initially of a high number of firms. We have modeled this in a three-stage game. In this model, firms compete in price in a differentiated product industry. Moreover, we assume that firms belonging to the same owner act cooperatively.

Our main conclusion is that, in contrast to the results obtained by Kamien and Zang (1990), merged equilibria can appear in this game. Moreover monopolization of the industry occurs with a high number of firms.

Our model can be extended to the case of coalitions structures in which a coalition, maximizing its joint payoff given the outside choice, decides the number of active firms which compete, but the other firms are not closed, they still exist but not compete (for example, they receive an allowance from the active firms).

\section{Acknowledgements :}

I would like to thank Laurent Flochel for encouragement and helpful discussions. 


\section{Appendix A. Proof of lemma 1}

The maximisation program of a merger $M_{1}$ with $k_{1}$ active firms is :

$$
\max _{p_{1}^{M_{1}}, p_{2}^{M_{1}}, \ldots, p_{k_{1}}^{M_{1}}}\left(\pi^{M_{1}}\right)
$$

where

$$
\begin{aligned}
\pi^{M_{1}}= & \sum_{i=1}^{k_{1}}\left(p_{i}^{M_{1}}-c\right) \frac{1}{1+\gamma\left(k_{1}+k_{2}+Z-1\right)} * \\
& {\left[1-\frac{1+\gamma\left(k_{1}+k_{2}+Z-2\right)}{1-\gamma} p_{i}^{M_{1}}+\frac{\gamma}{1-\gamma}\left(\sum_{i \neq j} p_{j}^{M_{1}}+\sum_{j \in M_{2}} p_{j}+\sum_{j \in \text { out }} p_{j}\right]\right.}
\end{aligned}
$$

We design by $j \in$ out the firms which are outsiders.

We obtain $k_{1}$ First Order Conditions (FOC) which are symmetric, so $p_{i}^{M_{1}}=$ $p^{M_{1}}, \forall i \in M_{1}$. After simplifications, we obtain the best response functions:

$$
p^{M_{1}}\left(p^{-M_{1}}\right)=\frac{1-\gamma+\gamma \sum_{i \notin M_{1}}\left(p_{i}\right)}{2\left[1+\gamma\left(k_{2}+Z-1\right)\right]}+\frac{c}{2}
$$

The best-reply function is symmetric for the merger $M_{2}$.

The maximisation program of an outside firm is:

$$
\begin{aligned}
\max _{p_{i}}\left(p_{i}-c\right) \frac{1}{1+\gamma\left(\sum_{i=1}^{2} k_{i}+Z-1\right)} * \\
\\
{\left.\left[1-\frac{1+\gamma\left(\sum_{i=1}^{2} k_{i}+Z-2\right)}{1-\gamma} p_{i}+\frac{\gamma}{1-\gamma}\left(\sum_{j \in M_{1}} p_{j}+\sum_{j \in M_{2}} p_{j}+\sum_{j \neq \text { iandj } \in \text { out }} p_{j}\right)\right]\right] }
\end{aligned}
$$

As before, prices of outsiders are equal, we then replace, $p_{i}^{*}$ by $p^{\text {out }}$ for all $i \notin$ $\left(M_{1}, M_{2}\right)$. We obtain :

$$
p^{\text {out }}\left(p^{- \text {out }}\right)=\frac{1-\gamma+\gamma\left(\sum_{j \in M_{1}} p_{j}+\sum_{j \in M_{2}} p_{j}+c\left[1+\gamma\left(\sum_{i=1}^{2} k_{i}+Z-2\right)\right]\right.}{2\left[1+\gamma\left(\sum_{i=1}^{2} k_{i}+Z-2\right)\right]-\gamma(Z-1)}
$$

In order to simplify, we replace

$$
\left(p^{M_{1}}\left(p^{-M_{1}}\right), p^{M_{2}}\left(p^{-M_{2}}\right), p^{\text {out }}\left(p^{-o u t}\right)\right)
$$

by

$$
\left(p_{1}, p_{2}, p\right) .
$$


The intersection of best response functions yields to :

$$
\left\{\begin{array}{l}
p_{1}^{*}=\frac{(1-\gamma)+\gamma\left(k_{2} p_{2}+Z p\right)}{2\left[1+\gamma\left(k_{2}+Z-1\right)\right]} \\
p_{2}^{*}=\frac{(1-\gamma)+\gamma\left(k_{1} p_{1}+Z p\right)}{2\left[1+\gamma\left(k_{1}+Z-1\right)\right]} \\
p^{*}=\frac{(1-\gamma)+\gamma\left(k_{1} p_{1}+k_{2} p_{2}\right)}{2\left[1+\gamma\left(k_{1}+k_{2}+Z-2\right)\right]-\gamma(Z-1)}
\end{array}\right.
$$

\section{Appendix B. Proof of proposition 2}

Numerical simulations give the number of active firms in the merger $M_{2}$ in order having $k_{1}^{*}<K_{1}$.

\begin{tabular}{|l|l|l|}
\hline $\mathrm{Z}=$ & $k 2 \geq$ & $k 2 \geq$ \\
\hline \hline 0 & 11 & 1 \\
1 & 17 & 8 \\
2 & 23 & 14 \\
3 & 30 & 20 \\
4 & 36 & 26 \\
5 & 42 & 33 \\
\hline
\end{tabular}

We read this table like this for example:" for $\mathrm{Z}=3$ and $\gamma=0.9, k_{2}$ must be higher than 20 to $\pi^{M_{1}}$ have an interior maximum $\left(k_{1}^{*}<K_{1}\right)$ ".

Note that for $\gamma=0.1, k_{2}$ must be very high to merger $M_{1}$ have a maximum.

\section{Appendix C. Tables}

Table 1

Reaction functions of the two mergers for $Z=1$ : 


\begin{tabular}{|l|l|l|l|l|l|}
\hline$K_{1}$ & $K_{2}$ & $k_{1}$ & $k_{2}$ & $\pi^{M_{1}}$ & $\pi^{M_{2}}$ \\
1 & 14 & 1 & 14 & 0.004226 & 0.024267 \\
2 & 13 & 2 & 13 & 0.004656 & 0.016495 \\
3 & 12 & 2.19 & 12 & 0.004818 & 0.015507 \\
4 & 11 & 2.36 & 11 & 0.005013 & 0.014701 \\
5 & 10 & 2.61 & 10 & 0.005255 & 0.013668 \\
6 & 9 & 3.02 & 9 & 0.005562 & 0.012277 \\
7 & 8 & 3.8 & 8 & 0.005965 & 0.010335 \\
8 & 7 & 8 & 3.8 & 0.010335 & 0.005965 \\
9 & 6 & 9 & 3.02 & 0.012277 & 0.005562 \\
10 & 5 & 10 & 2.61 & 0.013668 & 0.005255 \\
11 & 4 & 11 & 2.36 & 0.014701 & 0.005013 \\
12 & 3 & 12 & 2.19 & 0.015507 & 0.004818 \\
13 & 2 & 13 & 2 & 0.016495 & 0.004656 \\
14 & 1 & 14 & 1 & 0.024267 & 0.004226 \\
\hline
\end{tabular}

Table 2

Reaction functions of the two mergers for $Z=0$ :

\begin{tabular}{|l|l|l|l|l|l|}
\hline$K_{1}$ & $K_{2}$ & $k_{1}$ & $k_{2}$ & $k_{1}$ & $k_{2}$ \\
1 & 15 & $\oslash$ & $\oslash$ & 0.156969 & 15 \\
2 & 14 & 2 & 0.247657 & 0.157632 & 14 \\
3 & 13 & 3 & 0.203337 & 0.158403 & 13 \\
4 & 12 & 4 & 0.186461 & 0.159311 & 12 \\
5 & 11 & 5 & 0.177512 & 0.160394 & 11 \\
6 & 10 & 6 & 0.171958 & 0.161711 & 10 \\
7 & 9 & 7 & 0.168174 & 0.163346 & 9 \\
8 & 8 & 8 & 0.165428 & 0.165428 & 8 \\
9 & 7 & 9 & 0.163346 & 0.168174 & 7 \\
10 & 6 & 10 & 0.161711 & 0.171958 & 6 \\
11 & 5 & 11 & 0.160394 & 0.177512 & 5 \\
12 & 4 & 12 & 0.159311 & 0.186461 & 4 \\
13 & 3 & 13 & 0.158403 & 0.203337 & 3 \\
14 & 2 & 14 & 0.157632 & 0.247657 & 2 \\
15 & 1 & 15 & 0.156969 & $\oslash$ & $\oslash$ \\
\hline
\end{tabular}

For $Z=0$ and $K_{i}>1, \forall i=1,2$, two cases are possible for each structure $\left(K_{1}, K_{2}\right)$. 
Table 3

Best-response functions $\left(k_{1}^{*}\left(K_{1}, Z\right)\right)$ :

\begin{tabular}{|c|c|c|c|c|c|c|c|c|c|c|}
\hline & \multicolumn{2}{|l|}{$\mathrm{Z}=0$} & $\mathrm{Z}=1$ & $\mathrm{Z}=2$ & $\mathrm{Z}=3$ & $\mathrm{Z}=4$ & $\mathrm{Z}=5$ & $\mathrm{Z}=6$ & $\mathrm{Z}=7$ & $Z=8$ \\
\hline$K_{1}$ & \multicolumn{2}{|l|}{$k_{1}=$} & $k_{1}=$ & $k_{1}=$ & $k_{1}=$ & $k_{1}=$ & $k_{1}=$ & $k_{1}=$ & $k_{1}=$ & $k_{1}=$ \\
\hline 1 & \multicolumn{2}{|c|}{0.156969} & 1 & 1 & 1 & 1 & 1 & 1 & 1 & 1 \\
\hline 2 & \multicolumn{2}{|c|}{$(0.157632 ; 2)$} & 2 & 2 & 2 & 2 & 2 & 2 & 2 & 2 \\
\hline 3 & \multicolumn{2}{|c|}{$(0.158403 ; 3)$} & 2.19 & 3 & 3 & 3 & 3 & 3 & 3 & 3 \\
\hline 4 & \multicolumn{2}{|c|}{$(0.159311 ; 4)$} & 2.36 & 4 & 4 & 4 & 4 & 4 & 4 & 4 \\
\hline 5 & \multicolumn{2}{|c|}{$(0.160394 ; 5)$} & 2.61 & 5 & 5 & 5 & 5 & 5 & 5 & 5 \\
\hline 6 & \multicolumn{2}{|c|}{$(0.161711 ; 6)$} & 3.02 & 6 & 6 & 6 & 6 & 6 & 6 & 6 \\
\hline 7 & \multicolumn{2}{|c|}{$(0.163346 ; 7)$} & 3.8 & 7 & 7 & 7 & 7 & 7 & 7 & 7 \\
\hline 8 & \multicolumn{2}{|c|}{$(0.165428 ; 8)$} & 8 & 8 & 8 & 8 & 8 & 8 & 8 & $\oslash$ \\
\hline 9 & \multicolumn{2}{|c|}{$(0.168174 ; 9)$} & 9 & 9 & 9 & 9 & 9 & 9 & $\oslash$ & $\oslash$ \\
\hline 10 & \multicolumn{2}{|c|}{$(0.171958 ; 10)$} & 10 & 10 & 10 & 10 & 10 & $\oslash$ & $\theta$ & $\theta$ \\
\hline 11 & \multicolumn{2}{|c|}{$(0.177512 ; 11)$} & 11 & 11 & 11 & 11 & $\oslash$ & $\oslash$ & $\oslash$ & $\oslash$ \\
\hline 12 & \multicolumn{2}{|c|}{$(0.186461 ; 12)$} & 12 & 12 & 12 & $\oslash$ & $\oslash$ & $\oslash$ & $\oslash$ & $\oslash$ \\
\hline 13 & \multicolumn{2}{|c|}{$(0.203337 ; 13)$} & 13 & 13 & $\oslash$ & $\oslash$ & $\oslash$ & $\oslash$ & $\oslash$ & $\oslash$ \\
\hline 14 & \multicolumn{2}{|c|}{$(0.247657 ; 14)$} & 14 & $\oslash$ & $\oslash$ & $\oslash$ & $\oslash$ & $\oslash$ & $\theta$ & $\theta$ \\
\hline \multirow[t]{2}{*}{15} & \multicolumn{2}{|l|}{15} & $\theta$ & $\oslash$ & $\oslash$ & $\oslash$ & $\theta$ & $\oslash$ & $\theta$ & $\oslash$ \\
\hline & $\mathrm{Z}=9$ & $\mathrm{Z}=10$ & $\mathrm{Z}=11$ & $\mathrm{Z}=12$ & $\mathrm{Z}=$ & & & & & \\
\hline$K_{1}$ & $k_{1}=$ & $k_{1}=$ & $k_{1}=$ & $k_{1}=$ & $k_{1}=$ & $k_{1}$ & & & & \\
\hline 1 & 1 & 1 & 1 & 1 & 1 & 1 & & & & \\
\hline 2 & 2 & 2 & 2 & 2 & 2 & $\oslash$ & & & & \\
\hline 3 & 3 & 3 & 3 & 3 & $\oslash$ & $\oslash$ & & & & \\
\hline 4 & 4 & 4 & 4 & $\oslash$ & $\oslash$ & $\theta$ & & & & \\
\hline 5 & 5 & 5 & $\theta$ & $\oslash$ & $\oslash$ & $\oslash$ & & & & \\
\hline 6 & 6 & $\oslash$ & $\oslash$ & $\oslash$ & $\oslash$ & $\oslash$ & & & & \\
\hline
\end{tabular}


Table 4

Profit of the merger $M_{1}$ function of the number of outsider firms $(\mathrm{Z})$ and the number of firms owned by the merger $\left(K_{1}\right)$ :

\begin{tabular}{|c|c|c|c|c|c|c|c|c|}
\hline$K_{1}=$ & \multicolumn{2}{|l|}{$\mathrm{Z}=0$} & \multicolumn{2}{|c|}{$\mathrm{Z}=1$} & \multicolumn{2}{|l|}{$\mathrm{Z}=2$} & \multicolumn{2}{|l|}{$\mathrm{Z}=3$} \\
\hline 1 & \multicolumn{2}{|l|}{0.024136} & \multicolumn{2}{|c|}{0.004226} & \multicolumn{2}{|c|}{0.00229277} & \multicolumn{2}{|c|}{0.00153169} \\
\hline 2 & \multicolumn{2}{|c|}{$(0.0242078,0.11683)$} & \multicolumn{2}{|c|}{0.004656} & \multicolumn{2}{|c|}{0.00310011} & \multicolumn{2}{|c|}{0.00232071} \\
\hline 3 & \multicolumn{2}{|c|}{$(0.0242909,0.132968)$} & \multicolumn{2}{|c|}{0.004818} & \multicolumn{2}{|c|}{0.00355813} & \multicolumn{2}{|c|}{0.00286077} \\
\hline 4 & \multicolumn{2}{|c|}{$(0.0243881,0.140544)$} & \multicolumn{2}{|c|}{0.00393371} & \multicolumn{2}{|c|}{0.00332096} & \multicolumn{2}{|c|}{0.00291471} \\
\hline 5 & \multicolumn{2}{|c|}{$(0.0245034,0.144974)$} & \multicolumn{2}{|c|}{0.005255} & \multicolumn{2}{|c|}{0.00431892} & \multicolumn{2}{|c|}{0.00377761} \\
\hline 6 & \multicolumn{2}{|c|}{$(0.0246423,0.147886)$} & \multicolumn{2}{|c|}{0.005562} & 0.004 & 76051 & 0.0042 & 7738 \\
\hline 7 & $(0.024813,0.1)$ & 49947) & 0.00 & 5965 & 0.005 & 29569 & 0.0048 & 6037 \\
\hline 8 & $(0.0250277,0$ & 151484) & 0.010 & 0335 & 0.005 & 674 & 0.0055 & 7287 \\
\hline 9 & $(0.025306,0.1$ & $52673)$ & 0.01 & 2277 & 0.006 & 33702 & 0.0064 & 7999 \\
\hline 10 & $(0.025681,0.1)$ & $53622)$ & 0.01 & 3668 & 0.008 & 0361 & 0.0076 & 859 \\
\hline 11 & $(0.0262137,0$ & 154396) & 0.01 & 4701 & 0.009 & 34303 & 0.0093 & 7582 \\
\hline 12 & $(0.0270303,0$ & 155039) & 0.01 & 5507 & 0.012 & 1038 & 0.0119 & 203 \\
\hline 13 & $(0.0284404,0$ & 155582) & 0.016 & 6495 & 0.016 & 1899 & $\oslash$ & \\
\hline 14 & $(0.0314653,0$ & 156048) & 0.02 & 4267 & $\oslash$ & & $\oslash$ & \\
\hline 15 & 0.15645 & & $\oslash$ & & $\oslash$ & & $\oslash$ & \\
\hline$K_{1}=$ & $\mathrm{Z}=4$ & $\mathrm{Z}=5$ & & $\mathrm{Z}=6$ & & $\mathrm{Z}=7$ & & $\mathrm{Z}=8$ \\
\hline 1 & 0.00114897 & 0.00092 & 698 & 0.0007 & 3159 & 0.0006 & 94726 & 0.000630024 \\
\hline 2 & 0.00187127 & 0.00158 & & 0.0013 & 909 & 0.0012 & 6817 & 0.00117559 \\
\hline 3 & 0.00242304 & 0.00213 & & 0.0019 & 009 & 0.0017 & 8781 & 0.00168679 \\
\hline 4 & 0.00291471 & 0.00263 & & 0.0024 & 739 & 0.0022 & 9754 & 0.00219966 \\
\hline 5 & 0.00340615 & 0.00314 & & 0.0029 & 083 & 0.0028 & 3193 & 0.00274541 \\
\hline 6 & 0.00393964 & 0.00370 & & 0.0035 & 569 & 0.0034 & 2451 & 0.00335683 \\
\hline 7 & 0.00455497 & 0.00434 & & 0.0042 & 094 & 0.0041 & 1473 & 0.00407466 \\
\hline 8 & 0.0053 & 0.00511 & & 0.0050 & 784 & 0.0049 & 5664 & $\oslash$ \\
\hline 9 & 0.00624307 & 0.00609 & & 0.0060 & & $\oslash$ & & $\oslash$ \\
\hline 10 & 0.00749451 & 0.00740 & & $\oslash$ & & $\oslash$ & & $\oslash$ \\
\hline 11 & 0.00925262 & $\oslash$ & & $\oslash$ & & $\oslash$ & & $\oslash$ \\
\hline$K_{1}=$ & $\mathrm{Z}=9$ & $\mathrm{Z}=10$ & & $\mathrm{Z}=11$ & & $\mathrm{Z}=1$ & & $\mathrm{Z}=13$ \\
\hline 1 & 0.000584244 & 0.0005 & 1693 & 0.000 & 28856 & 0.000 & 513482 & 0.000504097 \\
\hline 2 & 0.0011098 & 0.0010 & 365 & 0.001 & 326 & 0.001 & 01364 & 0.00100481 \\
\hline 3 & 0.00161599 & 0.0015 & 837 & 0.001 & 3931 & 0.001 & 52578 & $\oslash$ \\
\hline 4 & 0.00213386 & 0.0020 & 374 & 0.002 & 7506 & $\oslash$ & & $\oslash$ \\
\hline 5 & 0.00269268 & 0.0026 & 814 & $\oslash$ & & $\oslash$ & & $\oslash$ \\
\hline 6 & 0.00332535 & $\oslash$ & & $\oslash$ & & $\oslash$ & & $\oslash$ \\
\hline$K_{1}=$ & $\mathrm{Z}=14$ & & & & & & & \\
\hline 1 & 0.000499723 & & & & & & & \\
\hline
\end{tabular}

where for $Z=0$, the first number designs the profit of the merger $M_{1}$ when 
$k_{1}^{*}<K_{1}$ and $k_{2}^{*}=K_{2}$ and for the second number it is the inverse. 


\section{References}

Caillaud, B., Jullien, B. ,Picard, P., 1995. Competing vertical structures: precommitment and renegotiation. Econometrica 63, 621-646.

Deneckere, R., Davidson, D., 1985. Incentives to form coalitions with Bertrand competition. The Rand Journal of Economics 16, 473-486.

Farrell, J., Shapiro, C., 1990. Horizontal mergers: an equilibrium analysis. American Economic Review 80, 107-126.

Gonzalez-Maestre, M., Lopez-Cunat, J., 2001. Delegation and mergers in oligopoly. International Journal of Industrial organization 19, 1263-1279.

Häckner, J., 2000. A note on price and quantity competition in differentiated oligopolies. Journal of Economic Theory 93, 233-239.

Kamien, M., Zang, I., 1990. The limits of monopolization through acquisition. Quarterly Journal of Economics 105, Issue 2, 465-499.

Kamien, M., Zang, I., 1993. Monopolization by sequential acquisition. Journal of Law, Economics, and Organization 9, 205-229.

Perry, M., Porter, R., 1985. Oligopoly and the incentive for horizontal merger. American Economic Review 75, 219-227.

Salant, S., Switzer, S., Reynolds, R., 1983. Losses due to merger : the effects of an exogenous change in industry structure on Cournot-Nash equilibrium. Quarterly Journal of Economics 98, 185-199.

Ziss, S., 2001. Horizontal mergers and delegation. International Journal of Industrial Organization 19, 471-492. 